\title{
PRODUÇÃO DE MUDAS VERSUS SEMEADURA DIRETA E PROFUNDIDADE DE SEMEADURA DE AMARANTO (Amaranthus spp.)
}

\section{PRODUCTION OF SEEDLINGS VERSUS DIRECT SOWING AND DEPTH OF AMARANTH SOWING (Amaranthus spp.)}

Matheus Azevedo dos Santos ${ }^{1}$; Rodrigo Fernandes Daros ${ }^{2}$; Matheus Santos de Deus ${ }^{3}$; Carlos Augusto Queiroz Gurka ${ }^{4}$; Aloisio Bianchini ${ }^{5}$

DOI: https://doi.org/10.31692/978-65-991061-7-0.362-367

\section{INTRODUÇÃO}

O objetivo deste trabalho foi avaliar algumas características de interesse agronômico de amaranto (Amaranthus spp). Na metodologia foi utilizada diferentes profundidades de semeadura do amaranto, além da avaliação da melhor forma de implantação da cultura, se por mudas ou sementes. Os resultados demonstraram que as melhores profundidades de semeadura do amaranto são 5 e $10 \mathrm{~mm}$, e a melhor forma de implantação dessa cultura é através da produção de mudas com 15 dias de idade seguido de transplantio à campo.

\section{FUNDAMENTAÇÃO TEÓRICA}

O amaranto é um antigo pseudocereal de folha larga originado nas Américas do Sul e Central. Essa planta foi cultivada extensivamente durante os cinco séculos de auge da civilização asteca, no México e pelas sociedades mais adiantadas. Ela pode ser usada como fonte de grãos de alto conteúdo proteico, como vegetal frondoso e tem potencial para crescer como forragem (Putnam et al., 1989; Belisle, 1990; Henderson et al., 1993; Myers, 1996 apud Costa e Borges, 2005). O genus amaranthus foi cultivado, no princípio, como o trigo pelos Astecas entre 5.000 - 7.000 anos passados, antes da conquista da civilização Sul-Americana pelos espanhóis (Stallknecht e Schulz-Schaeffer, 1993 apud Costa e Borges, 2005).

O amaranto tem múltiplos usos, tanto na alimentação humana, animal, na indústria, na medicina e na ornamentação. Para o consumo humano o grão pode ser utilizado inteiro ou moído na forma de farinha, assado ou cozido. As folhas são usadas da mesma forma a que folha outros legumes. Com grãos inteiros ou moídos pode preparar pequenos-almoços, sopas, sobremesas, mingau, bolos, pudins, refrigerantes e outros; também cozinhados, os grãos misturados com mel, melado ou chocolate, dando-lhe diferentes formas em moldes de

\footnotetext{
${ }^{1}$ Graduando em Agronomia, UFMT, Cuiabá-MT, matheusazevedooficial@outlook.com

${ }^{2}$ Mestrando em Agricultura Tropical pelo PPGAT; UFMT, Cuiabá-MT, rfernandesd@hotmail.com

${ }^{3}$ Graduando em Agronomia, UFMT, Cuiabá-MT, matheus_edific@ outlook.com

${ }^{4}$ Graduando em Agronomia, UFMT, Cuiabá-MT, carlos.gurka@ gmail.com

${ }^{5}$ Dr. em Engenharia Agrícola, Prof. Associado, UFMT, Cuiabá-MT, aloisio.bianchini@gmail.com
} 
madeira ou metálicos conhecidos como nougat de amaranto no Peru, "alegria" no México e "tadoos" na Índia (SinghaL; Kulkarni, 1988 apud Silva, 2015).

No Brasil o cultivo de amaranto ainda é incipiente, no entanto, apresenta perspectivas de se estabelecer como uma alternativa para a rotação de culturas criando oportunidades para dietas alimentares mais saudáveis (Spehar et al., 2007 apud Silva, 2015). Portanto o objetivo desse trabalho foi avaliar a melhor forma da implantação da cultura do amaranto, se por mudas ou semeadura direta, bem como avaliar a germinação de cinco variedades de amaranto frente à diferentes profundidades de semeadura.

\section{METODOLOGIA}

Foram realizados dois experimentos neste trabalho. O primeiro experimento a ser realizado foi a comparação da semeadura direta versus plantio de mudas na produção de sementes de amaranto. Foram utilizados três canteiros a céu aberto localizados nas dependências da Faculdade de Agronomia e Zootecnia (FAAZ), cada um com 3,95 m de comprimento por 1,20 m de largura. O delineamento experimental em blocos ao acaso (DBC) foi o escolhido para este experimento, para evitar diferenças na luminosidade sobre as parcelas, haja visto que os canteiros têm proximidade de árvores. Dos três canteiros utilizados dois deles continham um bloco cada, e o terceiro continha dois blocos, totalizando quatro blocos. Foram estabelecidos três tratamentos para a condução do teste. O primeiro (T1) foi o plantio de mudas com 15 dias de idade, produzidas previamente em casa de vegetação, no dia do estabelecimento do experimento nos canteiros. O segundo (T2) foi a semeadura no dia do estabelecimento do experimento nos canteiros. O terceiro (T3) foi o transplantio de mudas com 15 dias de idade, após duas semanas do estabelecimento do experimento nos canteiros.

As mudas foram produzidas em bandejas, em viveiro localizado na própria Faculdade de Agronomia e Zootecnia - UFMT, e o substrato utilizado foi uma mistura composta de 3 partes de esterco animal mais palha, para uma parte de solo, onde foram semeados o amaranto. Para o transplantio das mudas para os canteiros em hora pré-estabelecida, selecionou-se aleatoriamente 20 exemplares das bandejas para cada tratamento dentro dos blocos. A mesma quantidade de plantas adotou-se para os tratamentos de semeadura. Assim, aos 15 dias, após a germinação, as parcelas de semeadura sofreram raleamento e, as plantas vigorosas retiradas no raleio, foram utilizadas para estabelecimento das parcelas do terceiro tratamento. $\mathrm{O}$ espaçamento adotado foi de $10 \mathrm{~cm}$ entre plantas e $45 \mathrm{~cm}$ entre fileiras de plantas.

Nesse experimento, o objetivo foi avaliar o melhor tipo de estabelecimento do 
Amaranthus Cruentus cv. BRS Alegria, comparando semeadura direta e plantio de mudas. Aos 57 dias após o estabelecimento do experimento, foram amostradas 10 plantas de cada tratamento com 4 repetições (blocos), totalizando 40 plantas por tratamento. Fez-se medidas do diâmetro de colo (região basal do caule rente à superfície) e comprimento, de todas as plantas amostradas. Em seguida, as mesmas foram picadas, acondicionadas em sacos de papel, identificadas por bloco e tratamento, e postas para secar em estufa de ventilação forçada a $60^{\circ} \mathrm{C}$ por $48 \mathrm{~h}$. Posteriormente, as amostras foram pesadas, e determinou-se o peso da massa seca.

O segundo experimento do trabalho foi montado com o objetivo de avaliar a melhor profundidade de semeadura para as variedades de Amaranto: BRS-Alegria, Diócus, Princes, Verde (Amaranthus cruentus) e Inca (Amaranthus caudatus). Foi utilizado o Delineamento em Blocos Casualizados (DBC) para a distribuição dos tratamentos. Os tratamentos escolhidos consistiram em três profundidades diferentes de semeadura, sendo que o primeiro foi a zero milímetros (na superfície do solo), o segundo a cinco milímetros, e o terceiro a dez milímetros de profundidade. Utilizou-se três blocos distribuídos em um canteiro. Totalizou-se 45 unidades experimentais.

Foi escolhido um canteiro nas dependências da Faculdade de Agronomia e Zootecnia UFMT, com medidas de 3,95 m de comprimento por 1,20 m de largura. Paralelamente, foi realizada a separação de sementes das cinco variedades de Amaranto: BRS-Alegria, Diócus, Princes, Verde (Amaranthus cruentus) e Inca (Amaranthus caudatus). Como as sementes de Amaranto são sementes miúdas, foi adotado o processo de pesagem e armazenamento do material a ser semeado em cada uma das 45 unidades, individualmente em recipientes plásticos, com a utilização de balança de precisão medindo exatamente $0,100 \mathrm{~g}$ de sementes por cada parcela. Foram semeadas 45 linhas ao todo, espaçadas cerca de $7 \mathrm{~cm}$ umas das outras.

\section{RESULTADOS E DISCUSSÕES}

A análise de variância demonstrou que não há relação de dependência entre as variedades utilizadas e as profundidades de semeadura adotada (Tukey, em nível de 5\% de probabilidade). No entanto, o comportamento das variedades e o comportamento das profundidades apresentaram diferenças significativas se analisadas separadamente (Tukey, em nível de $5 \%$ de probabilidade), conforme apresentado na tabela 1.

Tabela 1 - Número de plantas emergidas aos 15 DAS (dias após a semeadura) 


\begin{tabular}{lcccc}
\cline { 2 - 4 } & $\mathbf{0}$ & $\mathbf{5}$ & $\mathbf{1 0}$ & \\
\hline BRS-Alegria & 18,67 & 87,3 & 108,3 & $\mathbf{7 1 , 4 A}$ \\
Verde & 8,67 & 89,7 & 99,3 & $\mathbf{6 5 , 9 A}$ \\
Diocus & 17,67 & 78,0 & 87,3 & $\mathbf{6 1 , 0 A B}$ \\
Princes & 9,67 & 66,7 & 77,67 & $\mathbf{5 1 , 3 B}$ \\
Inca & 12,00 & 68,0 & 61,7 & $\mathbf{4 7 , 2 B}$ \\
\hline Média & $\mathbf{1 3 , 3 b}$ & $\mathbf{7 7 , 9 a}$ & $\mathbf{8 6 , 9 a}$ &
\end{tabular}

Médias seguidas de mesma letra maiúscula na coluna ou minúscula na linha, não diferem entre si pelo teste de Tukey, em nível de 5\% de probabilidade.

As variedades BRS - Alegria, Verde e Diócus, apresentaram os melhores resultados quando testadas à $0 \mathrm{~mm}$ de profundidade, $5 \mathrm{~mm}$ e $10 \mathrm{~mm}$, com a média de plantas dos três blocos, emergidas aos 15 dias após a semeadura, de 71,4 plantas, 65,9 plantas, e 61,0 plantas respectivamente, conforme a ordem das variedades apresentadas. Já os piores resultados se mostraram nas variedades Princes e Inca, com valores médios de plantas emergidas de 51,3 plantas e 47,2 plantas, respectivamente. As diferenças entre as variedades podem ter ocorrido, em função do potencial germinativo das sementes de cada uma, que pode ter sido diferente, ou mesmo das características varietais próprias.

As melhores profundidades de semeadura de amaranto foram de $10 \mathrm{~mm}$ e $5 \mathrm{~mm}$, com as médias de plantas emergidas após os 15 dias de semeadura de 86,9 plantas e 77,9 plantas, respectivamente. O pior resultado foi para a profundidade de $0 \mathrm{~mm}$, ou seja, aquela em que a semeadura foi feita a lanço, com a média dos três blocos de 13,3 plantas emergidas. Uma das razões para explicar tal discrepância nos resultados, pode estar na umidade presente nas fases de embebição da semente, que foi menor nas sementes submetidas à $0 \mathrm{~mm}$ de profundidade de semeio, já que na superfície do solo a perda de água por evaporação é muito maior, podendo ter constituído entrave à germinação.

Os resultados apresentados na Tabela 2, indicam que o tratamento T1 foi o que apresentou melhor desempenho nos três atributos avaliados, sendo não diferente, apenas, na altura de plantas, em relação ao tratamento T2. Os tratamentos T2 e T3 apresentaram mesmo desempenho para todos os atributos estudados. Assim, pode-se afirmar que no plantio realizado com mudas de $15 \mathrm{DAG}(\mathrm{T} 1)$ as plantas conseguiram se desenvolver melhor do que nos outros tratamentos. Estes resultados podem estar associados às condições ambientes que as plantas foram submetidas, de forma que favoreceu o crescimento das mudas produzidas no viveiro e transplantadas com 15 DAG no estabelecimento do experimento. Para plantios, em 
condições de campo, estes resultados evidenciam que é mais vantajoso implantar o campo de produção, com mudas previamente produzidas sob condições ideais para o crescimento inicial das plântulas.

Tabela 2 - Médias de altura de planta $(\mathrm{mm})$, diâmetro de colo das plantas $(\mathrm{mm})$ e massa seca (g/planta) de plantas de amaranto Amaranthus Cruentus cv. BRS Alegria após 57 dias de plantio por mudas ou semeadura.

\begin{tabular}{|c|c|c|c|}
\hline Tratamento & $\begin{array}{c}\text { Altura média de } \\
\text { plantas }(\mathbf{m m})\end{array}$ & $\begin{array}{c}\text { Diâmetro médio de } \\
\text { colo }(\mathbf{m m})\end{array}$ & $\begin{array}{c}\text { Média da } \\
\text { massa seca } \\
\text { (g/planta) }\end{array}$ \\
\hline T1 - mudas de 15 dias & $1220 \mathrm{~A}$ & $13,3 \mathrm{~A}$ & $28,93 \mathrm{~A}$ \\
\hline T2- semeadura direta & $927 \mathrm{AB}$ & $10,7 \mathrm{~B}$ & $14,83 \mathrm{~B}$ \\
\hline T3- mudas 15DAG & $805 \mathrm{~B}$ & $10,8 \mathrm{~B}$ & $11,93 \mathrm{~B}$ \\
\hline
\end{tabular}

Médias seguidas de mesma letra maiúsculas na coluna, não diferem entre si pelo teste de Tukey, em nível de $5 \%$ de probabilidade.

A comparação entre os tratamentos T2 e T3 mostra que, no caso de uso de sementes para o estabelecimento de áreas de cultivo, é possível efetuar o transplantio em locais de falha, utilizando mudas excedentes do próprio campo, uma vez que não houve diferença significativa entre a altura de plantas, diâmetro do colo ou massa seca para os tratamentos T2 e T3.

\section{CONCLUSÕES}

O plantio de mudas de 15 dias de idade no estabelecimento do experimento, obteve o melhor resultado em altura, diâmetro de colo e massa seca, se mostrando a alternativa mais viável ao estabelecimento da cultura do Amaranto à campo.

As variedades de Amaranto avaliadas apresentam melhor germinação nas profundidades de 5 e $10 \mathrm{~mm}$, portanto pode se concluir que o semeio na modalidade a lanço, cuja semente se encontrará na superfície do solo, não é o mais recomendado para esta cultura, pois o estande inicial de plantas deste tratamento foi muito inferior se comparado aos demais.

\section{REFERÊNCIAS}

AMAYA-FARFAN, J.; MARCÍLIO, R.; SPEHAR, C.R. Deveria o Brasil investir em novos grãos para sua alimentação? A proposta do amaranto (Amaranthus sp.). Segurança Alimentar e Nutricional, v.12, p.47-56, 2005.

CARRIJO, Clarêt et al. Cerne, Lavras, v. 15, n. 3, p. 366-371, jul./set. 2009, Estabelecimento de Eriotheca pubescens (Bombacaceae) por meio de semeadura direta e de mudas em cascalheira. Cerne, Lavras, v. 15, n. 3, p.366-371, set. 2009. 
COSTA, Djeson Mateus Alves da; BORGES, Andrecelly Sólon. AVALIAÇÃO DA PRODUÇÃO AGRÍCOLA DO AMARANTO (Amaranthus hypochondriacus). Holos, [s.1.], v. 1, p.97-111, 25 dez. 2007. Instituto Federal de Educacao, Ciencia e Tecnologia do Rio Grande do Norte (IFRN). http://dx.doi.org/10.15628/holos.2005.61.

COSTA, Djeson Mateus Alves da; DANTAS, José Araújo. Efeitos do substrato na germinação de sementes de amaranto (Amaranthus spp). Rev. Ciênc. Agron., Fortaleza, v. 40, n. 4, p.498-504, out. 2009.

LISBOA, Universidade de. O que é um Banco de Germoplasma? 2010. Disponível em: <http://www.mnhn.ul.pt/portal/page?_pageid=418,1391346\&_dad=portal\&_scha=PORT AL>. Acesso em: 04 jul. 2017.

MATTEI, Vilmar Luciano. COMPARAÇÃO ENTRE SEMEADURA DIRETA E PLANTIO DE MUDAS PRODUZIDAS EM TUBETES, NA IMPLANTAÇÃO DE POVOAMENTOS DE Pinnus taeda L. 1993. 164 f. Tese (Doutorado) - Curso de Engenharia Florestal, Universidade Federal do ParanÁ, Curitiba, 1993.

MIX, Cultura. Banco De Germoplasma e Sua Importância. 2012. Disponível em: <http://meioambiente.culturamix.com/ecologia/banco-de-germoplasma-e-sua importância>. Acesso em: 04 jul. 2017.

RODRIGUES, Daniele Brandstetter et al. Profundidade de semeadura no desenvolvimento inicial de pseudocereais. Revista Verde de Agroecologia e Desenvolvimento Sustentável, [s.l.], v. 11, n. 2, p.182-186, 5 nov. 2016. Grupo Verde de Agroecologia e Abelhas. http://dx.doi.org/10.18378/rvads.v11i3.4269.

SILVA, Josilaine Gonçalves da. ASPECTOS FISIOLÓGICOS E PRODUTIVOS DO AMARANTO SUBMETIDO A DIFERENTES PERIODOS DE ESTRESSE HIDRICO. 2015. 72 f. Dissertação (Mestrado) - Curso de Agronomia, Universidade Federal de Mato Grosso, Cuiabá, 2015.

SPEHAR, C.r.. Diferenças morfológicas entre Amaranthus cruentus cv. BRS Alegria, e as plantas daninhas A. hybridus, A. retroflexus, A. viridis e A. spinosus. Planta Daninha, [s.1.], v. 21, n. 3, p.481-485, dez. 2003. FapUNIFESP (SciELO). http://dx.doi.org/10.1590/s0100$\underline{83582003000300017 .}$

SPEHAR, Carlos Roberto et al. Amaranto BRS Alegria: alternativa para diversificar os sistemas de produção. Pesquisa Agropecuária Brasileira, Brasília, v. 38, n. 5, p.659-663, maio 2003.

XIX CONGRESSO BRASILEIRO DE SEMENTES, 2015, Foz do Iguaçu. Caracterização da embebição em sementes de amaranto. Foz do Iguaçu: Embrapa Clima Temperado, 2015 